\title{
COMPUTER SIMULATION WITH ARGUMENTATION SCAFFOLDING FOR ELEMENTARY STUDENTS' COLLABORATIVE SCIENTIFIC EXPLANATION
}

\author{
Fan-Jun Yang and Chien-Yuan Su \\ College of Education, Zhejiang University, Hangzhou, China
}

\begin{abstract}
In elementary science education, it has many potential benefits to engage students in scientific explanations through evaluating claims, evidence and reasonings. This study intends to develop a web-based platform that integrates such functions as science simulation and synchronous online discussion, embedded with argumentation scaffolding, so that elementary students could conduct simulated scientific experiments and construct scientific explanations collaboratively in an interactive online science learning environment. A modified argumentation scaffolding is designed based on Toulmin's framework and applied in this platform, which consists of six components: claim, evidence, reasoning, agreement, query, and rebuttal. Each component contains several semi-structured or structured text templates to provide guidelines for students' online practices in argumentation and explanation. An investigation will be made on whether this platform is useful in supporting students' collaborative construction of scientific explanations in simulated scientific experiments.
\end{abstract}

\section{KEYWORDS}

Scientific Explanation, Scaffolding, Science Simulation, Elementary Students

\section{INTRODUCTION}

With the speed-up advancement of digital technologies, computer-based simulations have been used as essential learning resources in science education, while abstract concepts or non-observable scientific phenomena could be visualized through simulation, thus rendering science learning more adaptable to learners at diverse cognition levels (Heradio et al., 2016). Moreover, by using simulations for scientific learning, students could enhance their learning engagements, gain a deeper understanding of scientific knowledge, facilitate conceptual conversions, and develop inquiry skills (Chang et al., 2020; Verstege et al., 2019; Wen et al., 2020).

The construction of scientific explanations by students is considered an essential practice that can not only strengthen their understanding of science content, but can also improve their critical thinking and logical reasoning (Beyer and Davis, 2008; McNeill and Krajcik, 2012). As some researchers have argued, however, constructing scientific explanations is a challenging task for younger students, because it entails an intensive integration of claims and evidence in an authentic context, such as argumentation, to make their explanations persuasive to others (Sandoval and Millwood, 2005). In order to enhance students' skills in constructing scientific explanations, certain argumentation frameworks developed from Toulmin's model have been used to facilitate students to make explanations by taking such approaches as sentence openers, graphic organizers or prompts in science writing, oral presentations, and classroom discussions (McNeill and Krajcik, 2012).

Although several studies have been recently made to integrate argumentation scaffoldings with computerized contexts, such as virtual chatrooms or forums, to make students more actively engaged in online argumentation and explanation, these studies usually used general materials in the forms of text, images and videos to develop interactive context and present scientific issues that could stimulate further debate. Further, few studies have attempted to use computer simulations to provide students with scientific learning as well as allow students to perform scientific explanations on specific content. This study will develop an elementary science learning environment integrated with computer-based simulation and design an argumentation scaffolding derived from Toulmin's model, so that elementary students could conduct virtual scientific experiments and carry out collaborative construction of scientific explanations with online peers synchronously in virtual scientific experiments. 


\section{ARGUMENTATION AND EXPLANATION IN SCIENCE}

Explanations are a central artifact of science, and their construction and evaluation entail core scientific practices of argumentation (Sandoval and Millwood, 2005). In scientific communities, in fact, explanations are often questioned, evaluated, and revised through argumentation (Berland and Reiser, 2008). Some researchers have therefore proposed that both opportunities of argumentation and appropriate pedagogical strategies are needed to assist students in constructing scientific explanations and make them more deeply engaged in scientific inquiry (Hsu et al., 2015). One of the widely used pedagogical strategies is to design and apply argumentation scaffoldings derived from Toulmin's Argumentation Pattern (TAP), which holds that an entire argument can be divided into six components: claim, data, warrant, backing, rebuttal, and qualifier. TAP provides guidelines for how to coordinate and organize a scientific explanation (Zembal-Saul, 2009). Based on TAP, McNeill and Krajcik (2012) present a simplified framework for scientific explanation, covering four components: claim, evidence, reasoning, and rebuttal. As shown in Figure 1, the first three components form the content of a complete scientific explanation, so students ought to generate appropriate and sufficient evidence to support their claims and use logical reasoning to strengthen the connections between their claims and evidence. The last component is rebuttals, which connect the other three components to indicate why an alternative explanation cannot appropriately explain the problem.
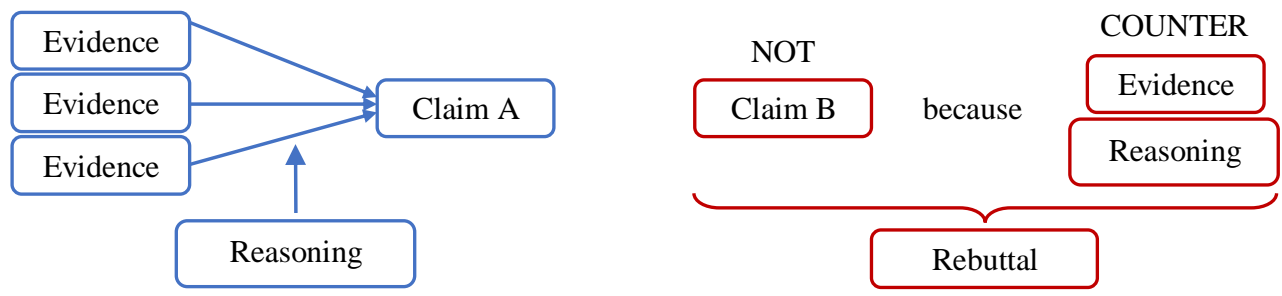

Figure 1. The instructional framework for the scientific explanation (McNeill and Krajcik, 2012)

Numerous studies have applied Toulmin's argument framework in computer-supported learning environments to help students construct arguments or explanations. For instance, Yeh and She (2010) have developed an online synchronous scientific argumentation program, which presents five components of TAP on the webpage, with 3-4 writing frames provided for each component to support students' arguments. Similarly, Yang et al. (2015) have built an Online Synchronous Scientific Inquiry and Argumentation Learning (OSSIAL) environment and designed several scripts or templates to help students compose arguments. Hsu et al. (2015) have also developed an Argumentative Scientific Inquiry System (ASIS) with structured argumentation scaffolding to improve students' skills in constructing scientific explanations. Several prompts and sentence openers are designed and integrated into ASIS by following a framework presented by McNeill and Krajcik (2012). Weng et al. (2017) have designed an online argumentation learning program (OALP) for collaborative group argumentation and provided students with a learning scaffolding consisting of four types of arguments and several writing templates. In general, most of these studies have set up certain forms of argumentation scaffoldings, such as sentence templates, prompts or hints, as an effective way to promote scientific explanation or argumentation in online learning environments.

\section{A LEARNING PLATFORM THAT COMBINES SCIENCE SIMULATIONS AND SCIENTIFIC EXPLANATIONS}

By employing several mature web technologies, including JavaScript, Socket and AJAX, this study creates an online collaborative learning environment, which can facilitate elementary students' scientific explanation by integrating science simulation and group discussion. As shown in Figure 2, the interface of this platform contains three modules: virtual science simulation, synchronous group discussion, and user-interactive information. Embedded in the first module is one of the Physics Education Technology Project $(\mathrm{PhET})$ simulations, called Balancing Act, to support students to conduct virtual physical experiments. By dragging and dropping objects, such as bricks and packages with different weights, students are able to place them on the sides of the rocker and further observe the balance of the rocker, so as to understand the principle of leverage. 
Moreover, some questions are set on this subject situation to trigger students to think deeply and encourage them to link up with the scientific explanations. In the module of the synchronous group discussion, students can conduct group scientific explanations after performing individual operations on scientific simulation subjects. A modified argumentation scaffolding is designed to help students construct scientific explanations effectively. When students work with others to construct scientific explanations, the argumentation scaffolding can help students construct claims, evidence and reasonings with various sentence templates. Additionally, students could make different types of responses, such as agreement, query and rebuttal, to any individual message in this discussion context. At the right side of the interface is a user-interactive information module, which shows a list of all online participants and an immediate-updating social network. All interactive actions, such as sending messages or replying to peers, will be visualized in this social network.

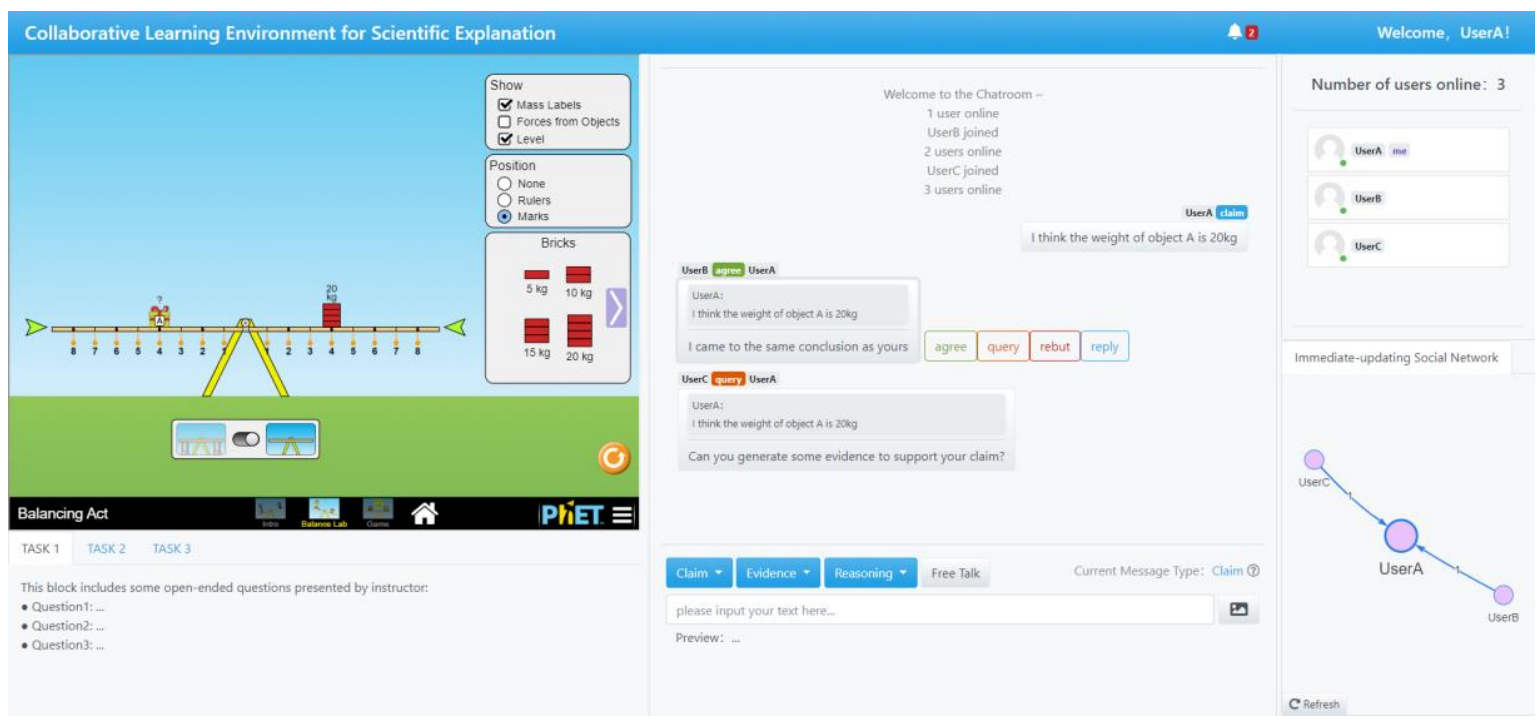

Figure 2. Collaborative learning environment for scientific explanation

\section{SCAFFOLDING DESIGN FOR SCIENTIFIC EXPLANATION}

In order to help elementary school students construct scientific explanations more effectively, a modified argumentation scaffolding is built into the synchronous group discussion module, which may improve students' interactions by facilitating the explanation construction in synchronous group discussions. As shown in Table 1 , the framework of the argumentation scaffolding is divided into two categories according to the users' statements/replies. Students can actively send messages to present their claims, evidence and reasonings in the whole-group interactive context, or they can reply (agree, query and rebut) to specific students' messages.

Table 1 . The framework of the modified argumentation scaffolding

\begin{tabular}{lll}
\hline Categories & Types & Description \\
\hline \multirow{3}{*}{ Statement } & Claim & A statement or conclusion that answers the original question/problem \\
& Evidence & $\begin{array}{l}\text { Scientific data (such as observations and measurements from experiments) that } \\
\text { supports the claim }\end{array}$ \\
& Reasoning & $\begin{array}{l}\text { A justification that connects the evidence to the claim in scientific principles } \\
\text { Reply }\end{array}$ \\
Agreement & $\begin{array}{l}\text { A consensus on others' statements } \\
\text { Query }\end{array}$ & $\begin{array}{l}\text { A question, especially expressing doubts or requesting information } \\
\text { A description of views or facts about why an alternative explanation is not } \\
\text { appropriate }\end{array}$ \\
\hline
\end{tabular}

Figure 3 presents two different ways of using argumentation scaffolding in the platform interface that could facilitate students to interact with other online participants. When making a statement, students can use some dropdown buttons above the input box to designate the claims, evidence or reasonings. Several semi-structured 
text templates related to each component of scientific explanation are presented to assist students in performing scientific explanation construction. As an alternative, they can just use a blank box to be free to comment. When making a reply, students should first select a message bubble and choose a reply type (agreement/query/rebuttal) before selecting a corresponding text template and sending out a reply to a specific peer's comment. Any message constructed with argumentation scaffolding will be tagged with its type.
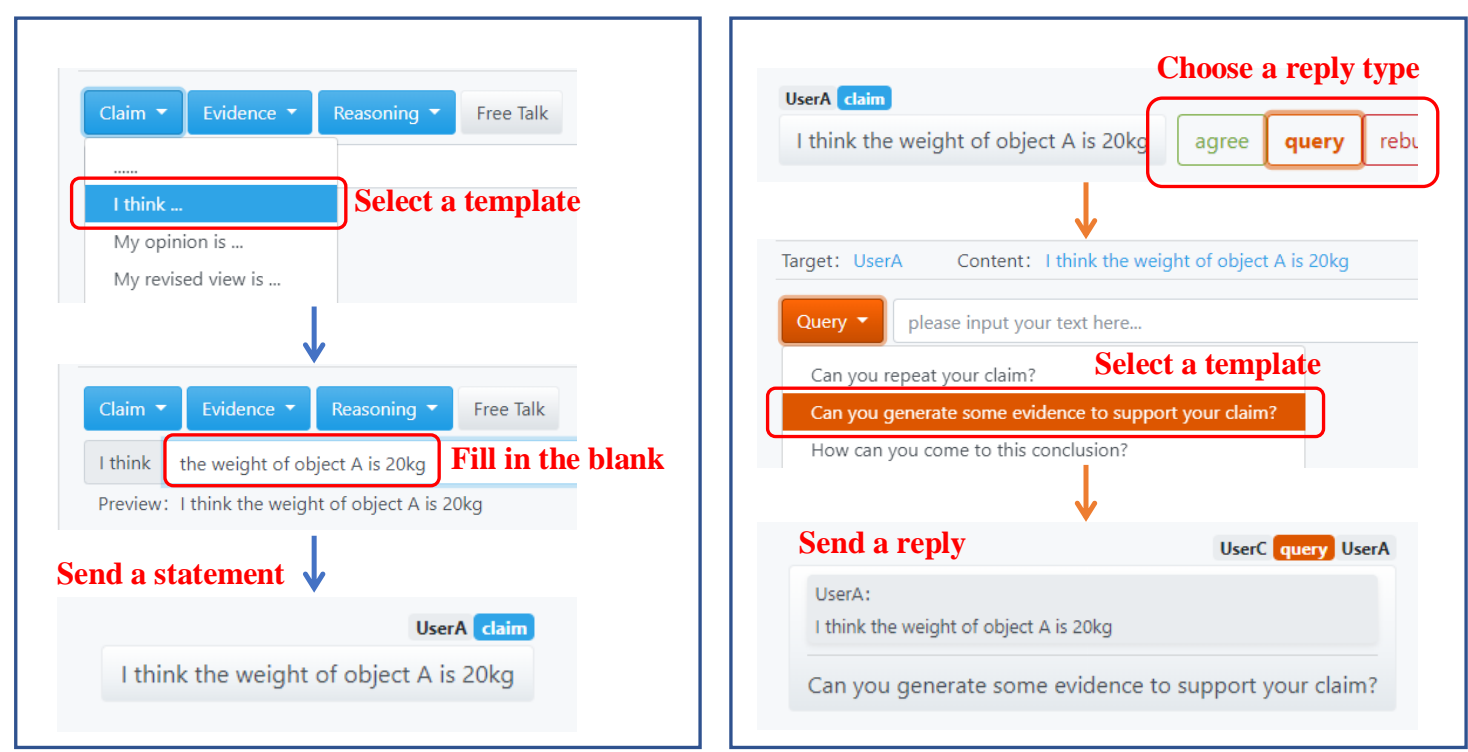

Figure 3. Use the scaffolding to make a statement (left) or reply (right)

In order to promote students' interactions in synchronous group discussions, such as exchanging views through replies, an immediate-updating social network is developed in the user-interactive information module. In JavaScript, the process of interactions is visualized to present a directed network graph, which could be updated whenever a new message is sent to the chatroom, so as to provide an instant overview of the interactions happening in the current group discussion. In the immediate-updating social network, all participants online are initialized as nodes with the same size and color. As the discussion proceeds, the active students, i.e., those who have contributed more replies to exchange views with peers, will be represented with larger pink nodes, indicating that they have actively participated in argumentation and explanation. Moreover, all replies are converted to connections between nodes with frequency tags. Thus, students could get detailed information about the interactions between peers, while reflecting on their self-participation, so as to adjust strategies for the follow-up discussion. This process may promote self-engagement and encourage students to elaborate on their explanations through argumentation.

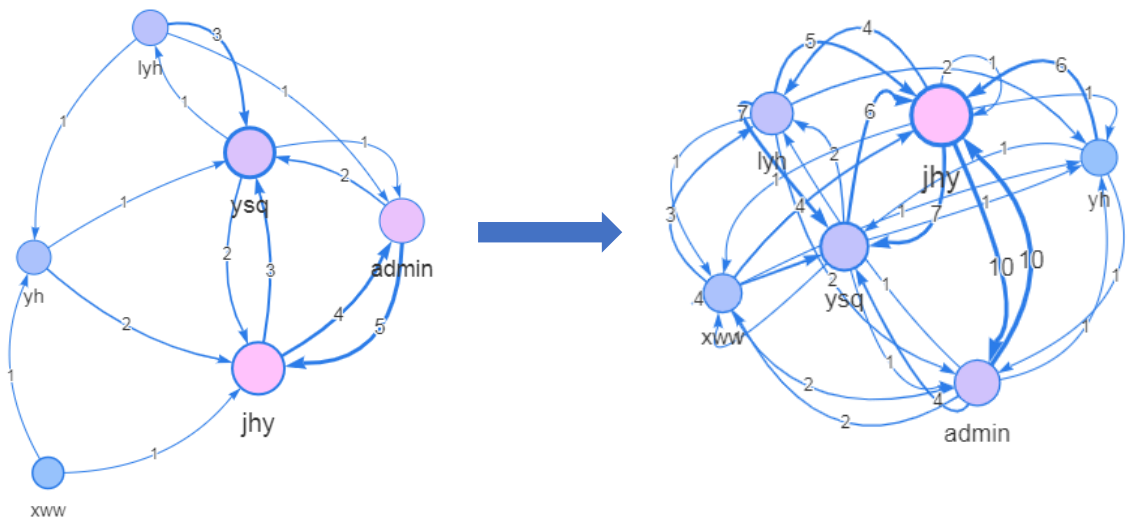

Figure 4. Changes during group discussion in the social network 


\section{CONCLUSION}

This study establishes an online learning environment, in which elementary school students can perform a computer-based simulation to understand science concepts (such as leverage, force and etc.) as well as construct scientific explanations on certain topics in computer simulations together with online peers. This learning platform can deliver the following potential benefits:

Collaborative learning environment: The online platform incorporates computer-based simulations and synchronous group discussions to enhance collaborative science learning, so that students are able to implement a series of science activities in a virtual environment.

Modified argumentation scaffolding: The modified argumentation scaffolding adapted from TAP can boost the ability of the elementary school students to construct scientific explanations.

Immediate-updating social network: The directed network is designed and deployed in our platform to provide a visual presentation of the group interaction process.

Further research is needed to explore the effectiveness of this platform in promoting elementary school students' science learning, and in particular, to test and prove the function of the argumentation scaffolding to support students' collaborative construction of scientific explanations.

\section{REFERENCES}

Berland, L. K. and Reiser, B. J., 2008. Making sense of argumentation and explanation. Science education, Vol. 93, No. 1, pp. 26-55.

Beyer, C. J. and Davis, E. A., 2008. Fostering Second Graders' Scientific Explanations: A Beginning Elementary Teacher's Knowledge, Beliefs, and Practice. Journal of the Learning Sciences, Vol. 17, No. 3, pp. 381-414.

Chang, C. et al, 2020. The impact of light-weight inquiry with computer simulations on science learning in classrooms. Computers \& Education, Vol. 146, 103770.

Heradio, R. et al, 2016. Virtual and remote labs in education: A bibliometric analysis. Computers \& Education, Vol. 98, pp. 14-38.

Hsu, C. et al, 2015. Enhancing skill in constructing scientific explanations using a structured argumentation scaffold in scientific inquiry. Computers \& Education, Vol. 91, pp. 46-59.

McNeill, K. L. and Krajcik, J. S., 2012. Supporting Grade 5-8 Students in Constructing Explanations in Science: The Claim, Evidence, and Reasoning Framework for Talk and Writing. Pearson Education, Boston, MA.

Sandoval, W. A. and Millwood, K. A., 2005. The Quality of Students' Use of Evidence in Written Scientific Explanations. Cognition and Instruction, Vol. 23, No. 1, pp. 23-55.

Verstege, S. et al, 2019. Relations between students' perceived levels of self-regulation and their corresponding learning behavior and outcomes in a virtual experiment environment. Computers in Human Behavior, Vol. 100, pp. 325-334.

Wen, C. et al, 2020. Students' guided inquiry with simulation and its relation to school science achievement and scientific literacy. Computers \& Education, Vol. 149, 103830.

Weng, W. et al, 2017. Scaffolding for argumentation in hypothetical and theoretical biology concepts. International Journal of Science Education, Vol. 39, No. 7, pp. 877-897.

Yang, W. et al, 2015. The Effects of Prior-knowledge and Online Learning Approaches on Students' Inquiry and Argumentation Abilities. International Journal of Science Education, Vol. 37, No. 10, pp. 1564-1589.

Yeh, K. H. and She, H. C., 2010. On-line synchronous scientific argumentation learning: Nurturing students' argumentation ability and conceptual change in science context. Computers \& Education, Vol. 55, No. 2, pp. 586-602.

Zembal-Saul, C., 2009. Learning to teach elementary school science as argument. Science education, Vol. 93, No. 4, pp. 687-719. 